\title{
Toward liveable neighbourhoods: Prioritizing the improvement of neighbourhood amenities through people-oriented planning in Wuhan
}

\author{
Qi ZHANG, Wuhan Land Use and Urban Spatial Planning Research Center, College of Architecture and Urban \\ Planning, Tongji University, China \\ Zhenhuang, ZHENG, Wuhan Land Use and Urban Spatial Planning Research Center, China Jianzhong, HUANG, \\ College of Architecture and Urban Planning, Tongji University, China Ying, Zhou, Wuhan Land Use and Urban \\ Spatial Planning Research Center, China
}

\begin{abstract}
The improvement of neigbourhood amenities is one of the key urban renewal issues in old districts. Due to tight deadlines and financial restrictions, the amenities' improvement in China have been often criticized for the misallocation of resources meeting resident's demand. Previous studies have investigated how residents' demand in amenities can be met through urban renewal. However, very few explored how the priorities or sequences of improvement should be identified to more effectively improve neighbourhood satisfaction. Thus, this study adopted Kano-IPA model to investigate the priorities of amenities improvement of urban neighbourhoods in Wuhan, China. Firstly, 5100 questionnaires soliciting the residents' subjective perception of the usage and satisfaction of amenities were collected. Secondly, the valid data has been analyzed by using different statistical techniques, including descriptive, correlation and regression modelling etc. Lastly, the adaptive strategy of amenities improvement can be proposed. The preliminary results showed that, for the sequence of amenities' usage frequency, there is no significant difference among different neighbourhoods. But significant differences were found at the structure and significance level of associations between amenities' evaluation and neighbourhood satisfaction among different sets of resident group. In regards to this, basic, excitement and performance factors fitting different scenarios have been identified. The research findings can provide references for allocating financial budget and other resource in improving neighbourhood amenities in urban renewal. This case study also illustrate the contextual characteristics of public goods provision in urban China. Future feasibility studies fitting the identified priorities into planning practice and both considering time and public expenditure limitation are expected.
\end{abstract}

Keywords

Satisfaction, amenities, perception, China, urban planning

\section{Introduction}

Neighbourhood environments have been widely considered as crucial basis of life to urban residents since this place that the residents spend most of their life time is associated with their well-being (Rashid et al., 2013). Generally, satisfaction with neighbourhood is a major domain of life satisfaction (Campbell, Converse, \& Rodgers, 1976).As essential components of neighbourhood life, neighbourhood amenities support the daily life by meeting the various demands of heterogeneous residents.In the arena of urban planning, the provision of amenities is a major domain of neighbourhood planning which aims to cultivate a livable neighbourhood. As the users of the neighbourhood, the residents' satisfaction with the usage of amenities is the key performance indicator for evaluating the effectiveness of the provision as well as the the quality of neighbourhood life (Asiyanbola et al., 2012; Iyanda and Mohit, 2016). Thus, the nexus between neighbourhood overall satisfaction and satisfaction with neighbourhood amenities is crucial to practicing people-oriented planning to improve the quality of neighbourhood life. 
In China, emerging challenges derived from rapid urbanization at neighbourhood scale, such as facilities deterioration, social exclusion, inadequate provision of open space etc., pushed the governments focus on the revitalization of old neighbourhood and reform of local governance. In recent years, neighbourhood life circle has been widely used as a conceptual tool to guide neighbourhood planning. To cope with the sharply decayed old neighbourhood, the improvement of amenities provision is the core issue that the authorities and professionals highly engaged in. According to the worldwide practise, assessing the existing circumstance and illustrating the blueprint are the precondition of initiating the neighbourhood planning, or even the part of the statutory neighbourhood planning (Rohe, 2009).

However, the limited theoretical foundation and practical experience hinders the cultivation of people-oriented planning in China. Specifically, how the residential perception and satisfaction can be concretely transformed into practical planning implications is a common obstacle. Given the focus of China planning has been long-term focusing on macro narrative and top-down oriented, neighbourhood planning has not been a nationwide practice until the recent decade. Whereas, in the field of customer satisfaction, the Importance-performance Analysis (IPA) and Kano model is a popular technique to evaluate the service quality by examining the correlates of residential satisfaction. Based on the evaluation, it can propose improvement priorities for optimizing the service. However, transdisciplinary application of IPA-Kano model in urban studies are limited to transport service, pedestrian satisfaction, noise and public open space (Wu \& Cao, 2017; Dong, et. al, 2019). Particularly, its application in determining the improvement priorities of neighbourhood amenities in China is rare. This research gap becomes more significant due to the increasing requirement of explicit and contextual guidelines in implementing the extensive urban renewal projects in China.

Thus, this study aims to investigate how the priorities of amenities improvement should be identified to more effectively improve neighbourhood satisfaction. The paper is organized as follows: in the second section, the relevant theories regarding amenities, neighbourhood satisfaction and their associations are shown; The third section presents the methodology adopted, including the data collection and analysis. In the fourth section, the general characteristics of residential usage and perception of neighbourhood amenities are demonstrated. The fifth section shows an example of applying IPA-Kano model in determining the improvement priority addressing the demand of elderly. The last section summarizes the policy implications and proposes several recommendations.

\section{Literature Review}

\section{1. life satisfaction, neighbourhood amenities and their associations}

The need satisfaction theory states that satisfaction with life is contingent on the extent to which individuals' needs are fulfilled (Diener et al., 2012). The multiple discrepancy theory extended the need satisfaction theory by introducing the perspective of social comparison. It demonstrates that life satisfaction is' inversely related to the degree of discrepancy from multiple standards, including what one wants, what one has had in the past, and what relevant others have'(Diener et al., 2012, p.66). In regards to the associations between objective environment and life satisfaction, Campbell's environmental psychology model argues that residential environment may affect life satisfaction indirectly through individuals' perception and evaluation of such environment (Campbell, Converse \& Rosders, 1976).

Among all the dimensions of life satisfaction, neighbourhood environments is an important one since it concentrates the attributes affecting residents' lives, such as quality of amenity, access to public transport and adequacy of open space, etc (Bardhan, Kurisu, \& Hanaki, 2015, p.57). This study used the term of 'neighbourhood satisfaction' to stand for the 'residential satisfaction with neighbourhood life'. In urban studies, the residential satisfaction with neighbourhood life refers to the resident' subjective assessment of one's life conditions based on the comparison between aspirations and achievements on various aspects of the neighbourhood they are living in. It is a integrated and multi-layer indicator system and meanwhile an accumulative consequence of personal feelings.

The neighbourhood amenities normally include education, medical, shopping, municipal, transport, sport, entertainment and administrative service facilities. The satisfaction of residents of any amenity should be among the main objectives of providing such amenity in the first instance (Oluwunmi et al., 2012). Therefore, neighbourhood satisfaction can be used to guide neighbourhood planning and help optimizing the usage of amenities (Yuan etc, 2018). 
However, some empirical studies in China showed that the impacts of neighbourhood environments on subjective well-being is weak in some scenarios. Liu et al. (2017) investigated the influence of residential environment on migrants' subjective well-being in Guangzhou. They found that there is no significant association between neighbourhood amenities and migrants' life satisfaction. Dong and Qin (2017) argued that the impact of neighbourhood environment on subjective well-being is significant but minor. Instead, safety, residential convenience and transit accessibility were the most influential attributes. Thus, there is a need for further specifying the associations among neighbourhood attributes.

\subsection{The Importance-Performance Analysis and Kano Model}

Thus, Importance-performance analysis (IPA) and Kano Model, which have been widely used in customer satisfaction evaluation in marketing realm (Mikulic, 2012), were adopted to identify the sequence of amenities improvement.

As shown in Figure 1, IPA used the four-quadrant formed by the horizontal axis (performance) and vertical axis (Importance) to divide all the factors of service and define the priorities. For instance,the factor would be categorized as 'possible overkill' if its performance was 'high' but its importance is 'low'. There are two assumptions of IPA : 1) attribute performance and importance are independent; 2) attribute performance has a linear and symmetric impact on overall performance. However, the literature on service satisfaction shows that service attributes have asymmetric relationships with overall performance (Matzler \& Renzl, 2007; Wu, Cao, \& Huting, 2018). Thus, threefactor theory of customer satisfaction was further adopted to address the assumptions.

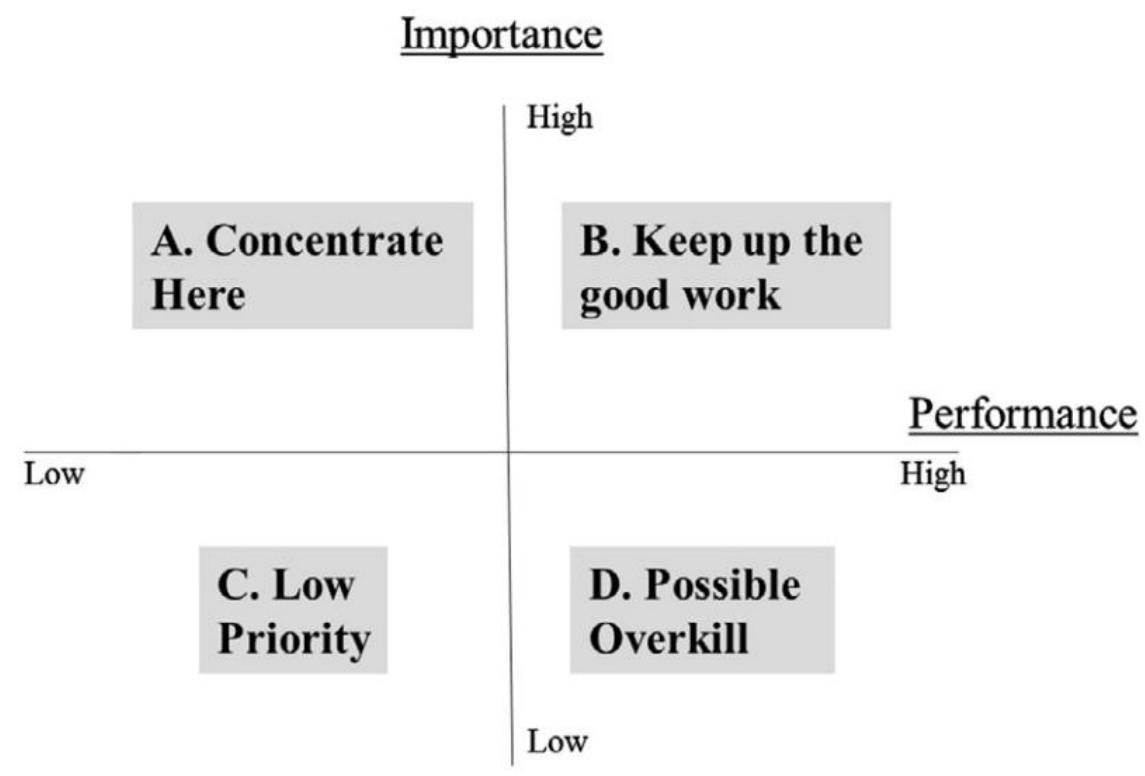

Source: Adapted from Martilla \& James (1977).

\section{Figure 1. Importance-performance analysis grid}

The three factor theory classifies the attributes into three categories with different level of importance to overall satisfaction: basic factors, performance factors, and excitement factors as shown in figure 2. The theory was originally developed by Kano et al. (1984) and adapted by subsequent studies on customer satisfaction (Brandt, 1988; Johnston, 1995; Matzler \& Sauerwein, 2002). Basic factors refer to those attributes which have significant impacts on overall satisfaction when they perform poorly. However, they do not increase overall satisfaction when they perform well. Performance factors refer to those attributes which have a linear and symmetric relationship with customer satisfaction no matter they perform either well or poorly. Exciting factors refer to those attributes which have significant impacts when they perform well. But they do not decrease overall satisfaction when they do not perform well. 


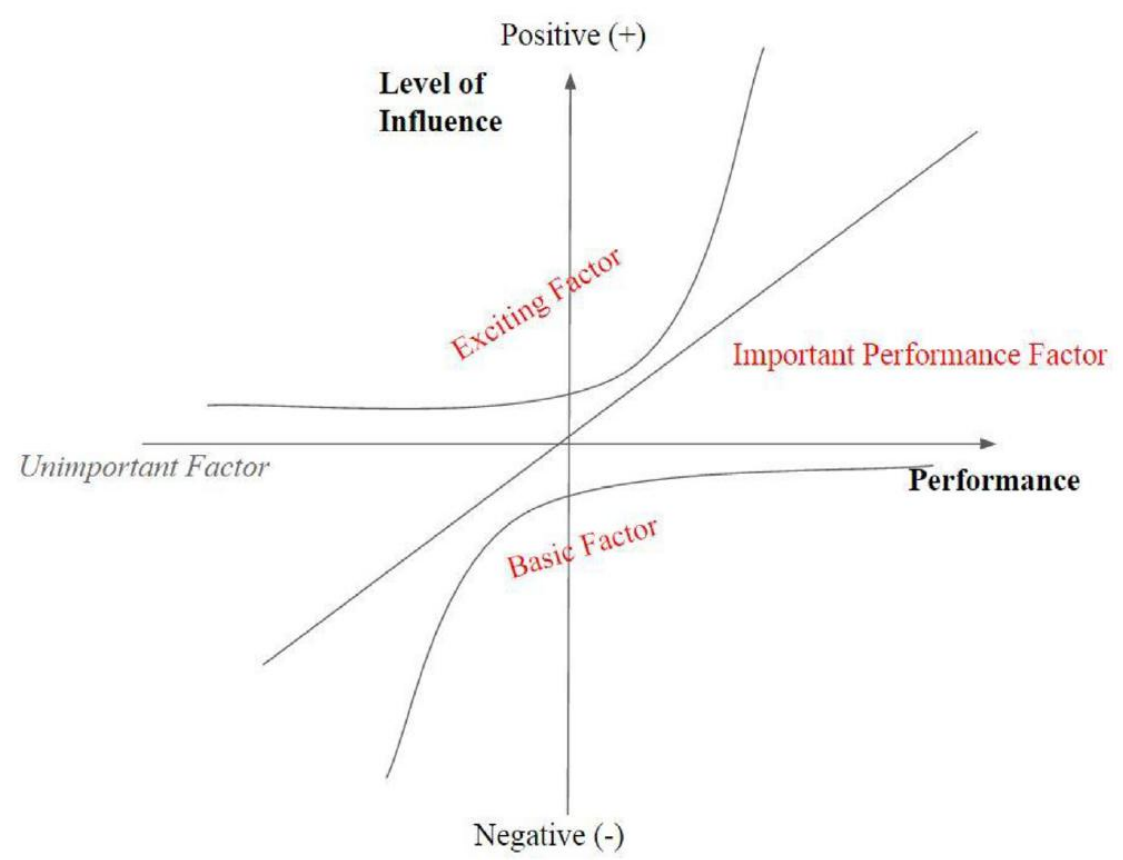

Figure 2. The three-factor theory of satisfaction

Although the three factor theory has been used in the field of service and production, its exploration in the area of neighbourhood satisfaction is limited. In particular, Yin et.al.(2016) used the three factor theory to examine environmental correlates of residential satisfaction in China. Dong et.al (2019) integrated the method with gradient boosting decision trees in analyzing the pedestrian satisfaction in gated and open communities. Very few focused on determining the priorities of amenities improvement by ascertaining their associations with neighbourhood satisfaction (Fernandez-Portero, Alarcon, \& Padura, 2017). Given the limitation of time and resource, prioritizing the improvement of various amenities, particularly at urban old districts, is crucial to corresponding authorities (Cao et al., 2018).

\section{Methodology}

\subsection{Study Area and case selection}

Commodity housing neighbourhood and traditional danwei neighbourhood were selected based on similar location in all the 13 districts of Wuhan municipal boundary. Total 34 neighbourhood were finally selected for conducting face-toface questionnaire survey. 
Toward liveable

neighbourhoods: Prioritizing the

improvement of neighbourhood

amenities through people-

oriented planning in Wuhan

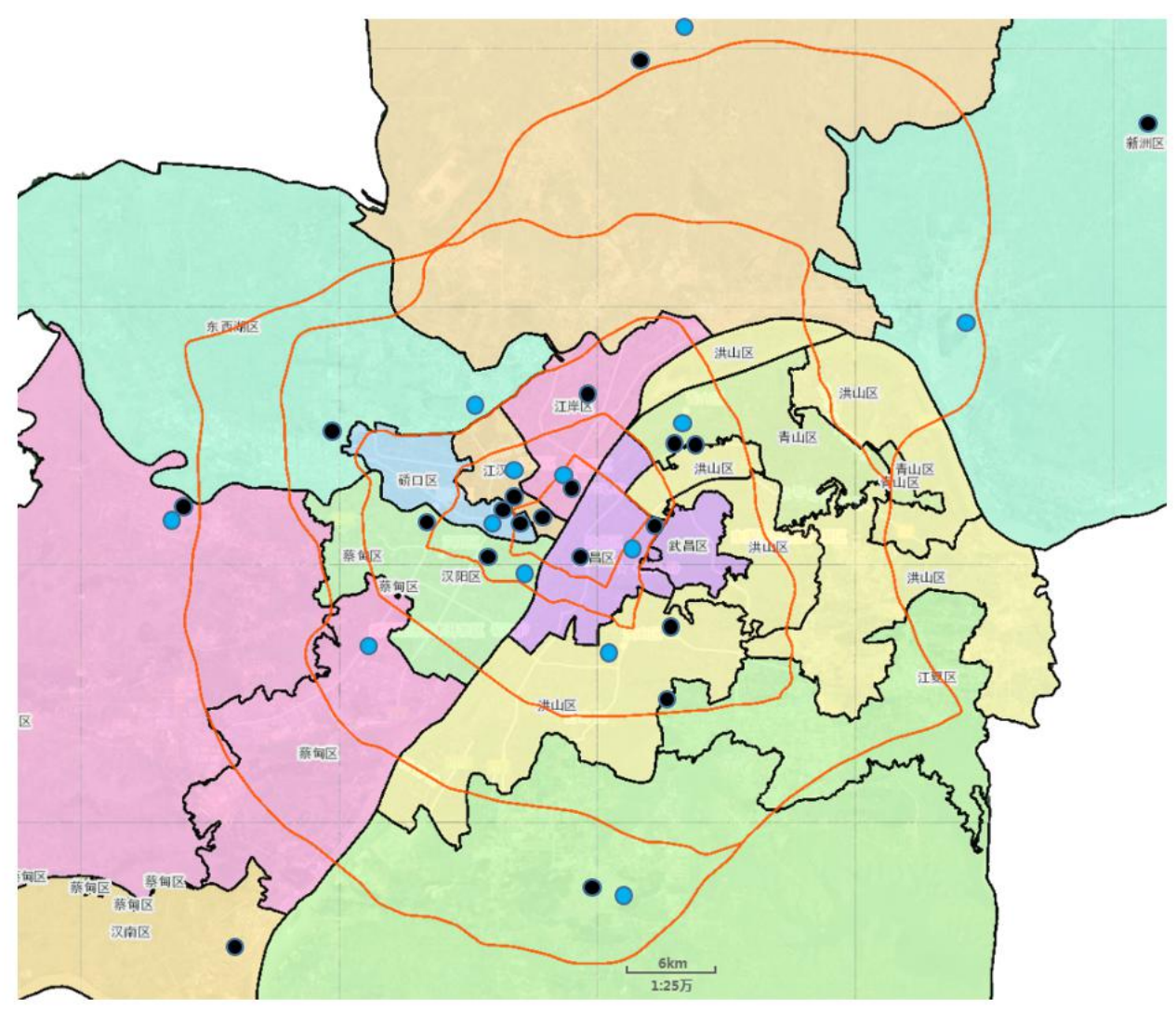

Figure the location of the 34 selected neighbourhoods within Wuhan administrative area

\subsection{Questionnaire Design and data collection}

Those questionnaires with any missing items (not filled in by either the interviewee or interviewer) were considered as invalid and removed from analyses.

\subsection{Data and model analysis}

The collected data has been tested by conducting reliability and KMO analysis. The Cronbach Alpha is 0.839 ( $>0.7)$ and The KMO is $0.851(0.8)$, which indicates the high level of reliability of the obtained data. For the multi-collinearity aspect, there is no circumstance of any independent variables' tolerance $<0.2$ or VIF $>10$ or eigenvalue $=0$. Thus, there is no multicollinearity existed among all the independent variables. The $p$ value of Bartlett test is 0.000 which shows that the dataset is suitable for Exploratory Factor Analysis.

This research used ordinal logistic regression modelling to identify basic, performance, and exciting factors. SPSS version 22.0 was used to manage and analyze the data. The model set the value 3 of Likert Scale as the reference group to investigate whether the independent variables significantly associate with dependent variable when they perform either well (value is 4 or 5) or poor respectively( value is 1 or 2). In addition, the socioeconomic variables shown in table 1 were also included into the model as controlled variables. The $p$ value of Parallel line hypothesis testing of all the generated models are larger than 0.05 which cannot reject the HO hypothesis.Thus, the usage of ordinal logistic regressions met the precondition and is applicable. The correlation function of ordinal logistic regression is shown below:

$$
Y^{\prime}=\log i t[\pi(x)]=\ln \frac{\pi(x)}{1-\pi(x)}=\alpha+\beta_{1} X_{1}+\beta_{2} X_{2}+\cdots+\beta_{p} X_{p}
$$

\section{Main Characteristics of the descriptive analysis}


Toward liveable

Zhang, Q; Zheng,Z.H; Huang, J.Z.; Ying, Z.

neighbourhoods: Prioritizing the

improvement of neighbourhood

amenities through people-

oriented planning in Wuhan

\subsection{Respondent's social-economic characteristics}

The study has totally distributed 5258 surveys to the approached respondents. Finally, the number of valid survey is 5100. Thus, the valid rate of collected samples is $97.00 \%$. For each neighbourhood, the number of valid questionnaire is 150. The social-economic characteristics of the respondents are shown below in Table 1.

\begin{tabular}{|c|c|c|c|}
\hline Category & Group & Frequency & Percentage $(\%)$ \\
\hline \multirow[t]{2}{*}{ Gender } & Male & 2342 & 45.9 \\
\hline & Female & 2758 & 54.1 \\
\hline \multirow[t]{5}{*}{ Age } & $18-25$ & 541 & 10.6 \\
\hline & $26-35$ & 1394 & 27.3 \\
\hline & $36-45$ & 1186 & 23.3 \\
\hline & $46-60$ & 1188 & 23.3 \\
\hline & 60 above & 791 & 15.5 \\
\hline \multirow[t]{5}{*}{ Education } & Lower than primary school & 1 & 0.0 \\
\hline & Elementary school & 84 & 1.6 \\
\hline & Secondary school & 2468 & 48.4 \\
\hline & College or high diploma & 2481 & 48.6 \\
\hline & Postgraduate & 66 & 1.3 \\
\hline \multirow{2}{*}{$\begin{array}{l}\text { Property right } \\
\text { of the occupant }\end{array}$} & Property owner & 4592 & 90.0 \\
\hline & Tenant & 508 & 10.0 \\
\hline \multirow{6}{*}{$\begin{array}{l}\text { Family } \\
\text { Structure }\end{array}$} & Living alone & 146 & 2.9 \\
\hline & Couple only & 915 & 17.9 \\
\hline & Nuclear family & 2361 & 46.3 \\
\hline & Living with parents & 632 & 12.4 \\
\hline & $\begin{array}{l}\text { Extended family consisting of } \\
\text { three generations }\end{array}$ & 720 & 14.1 \\
\hline & Others & 326 & 6.4 \\
\hline \multirow[t]{2}{*}{ Hukou Status } & Local hukou & 4477 & 87.8 \\
\hline & Non-local hukou & 623 & 12.2 \\
\hline \multirow{5}{*}{$\begin{array}{l}\text { Length of } \\
\text { Living }\end{array}$} & Less than one year & 46 & 0.9 \\
\hline & One to three years & 611 & 12.0 \\
\hline & Four to six years & 1325 & 26.0 \\
\hline & Seven to 10 years & 832 & 16.3 \\
\hline & Longer than 10 years & 2286 & 44.8 \\
\hline \multirow[t]{6}{*}{ Occupation } & Civil servant & 130 & 2.5 \\
\hline & Public institution' professional & 693 & 13.6 \\
\hline & Private company employees & 1280 & 25.1 \\
\hline & Workers & 355 & 7.0 \\
\hline & Self-employed entrepreneurs & 397 & 7.8 \\
\hline & Students & 108 & 2.1 \\
\hline
\end{tabular}




\begin{tabular}{|l|l|l|l|}
\hline \multirow{4}{*}{} & Freelancer & 276 & 5.4 \\
\cline { 2 - 4 } & Others & 667 & 13.1 \\
\hline \multirow{3}{*}{$\begin{array}{l}\text { Mersonal } \\
\text { Income }\end{array}$} & 3000 RMB below & 730 & 14.3 \\
\cline { 2 - 4 } & $3000-5000$ RMB & 2442 & 47.9 \\
\cline { 2 - 4 } & $5001-8000$ RMB & 1516 & 29.7 \\
\cline { 2 - 4 } & $8001-10000$ RMB & 339 & 6.6 \\
\cline { 2 - 4 } & 10000 RMB above & 73 & 1.4 \\
\hline Total & 5100 & $\begin{array}{l}56.58 \% \text { of the } \\
\text { respondents } \\
\text { feel satisfied or } \\
\text { Mean value of overallisfied) }\end{array}$ \\
\hline
\end{tabular}

Table 1 The socioeconomic characteristics of the respondents

\subsection{The general characteristics of facilities usage, satisfaction and demand}

The descriptive analysis shows that the mean value of overall satisfaction with the neighbourhood life is 3.44 and the proportion of respondents who indicated either 'satisfaction' or 'highly satisfaction' is $56.58 \%$. Thus, the general results show that the overall level of satisfaction with neighbourhood life in Wuhan is at medium level, which is a little way from satisfaction.

The descriptive analysis shows that the rate of usage of daily life and commercial service, commuting-related amenities and public open space is higher. In this study, the rate of usage refers to the proportion of respondents who regarded the corresponding facility as frequently used one. The specific amenities whose rate of usage is higher than $50 \%$ include supermarket and convenience store, fresh market, restaurant, logistic service store, subway station, bus station and neighbourhood parks. According to the Planning and Design Standards of urban residential area, these highly used amenities are mainly those categorized into life cycle facilities within five-minute and ten-minute walking distance.

Comparatively, the amenities which owns lower rate of usage (below than 5\%) consisted of rehabilitation center, elderly service center, healthcare center, local police station, bookstore, committee office of property owners, ball court, fitness center, private education institutes and laundries. This may be attributed to the following two reasons: 1) particular usage group of them, such as elderly, sports lover, housewives etc.; 2) the objective provision of them are deficient.

For the mean value of satisfaction with individual amenity, the first amenities which own highest mean value are shopping store, logistic service store, restaurants, Pharmacy, medical care service center, bus station (in descending order). In comparison, the last six amenities which own lowest mean value are park lots, reading room, public toilets, property management office, garbage collection point, elderly care center (in ascending order).

In regards to the amenities which were perceived as 'to be urgently improved' include public toilets, garbage collection point, parking lots, outdoor activities area, neighbourhood parks, fresh market, elderly activity room and property management office etc. (in descending order). Other than fresh market, all the perceived to be urgently improved amenities are those marked lowest mean value of satisfaction.

\subsection{The amenity satisfaction at commodity-housing neighbourhoods is generally higher than those in}

\section{danwei neighbourhood}

By conducting Mann-Whitney $U$ and Wilcoxon Rank Sum test, the analysis results show although there is no significant difference on amenity usage characteristics between commodity-housing neighbourhoods and traditional danwei neighbourhoods, the amenity satisfaction level at the former are generally and significantly higher than those in the latter. There are 20 types of amenities out of total 23 whose perceived mean value of satisfaction level is higher in commodity-housing neighbourhood. Only the restaurants, healthcare center and public toilets own higher mean value of satisfaction in 
traditional danwei neighbourhoods. Thus, the results reveal that, compared with old danwei neighbourhood pattern, the development pattern of commodity-housing can provide more satisfactory amenities to their residents.

\subsection{The low degree of moving intention and high degree of sense of belongings}

Although $79.4 \%$ and $77.0 \%$ of the respondents have never participated in the residential meeting and collective culture or sport activities respective, $66.9 \%$ of the respondents still indicated high degree of sense of belongings and felt as being a member of the neighbourhood. For the intention of moving out from the neighbourhood, only $7.7 \%$ of the respondents intended to move out instead of staying living in the current neighbourhood. In regards to the reason of staying living, affordable housing (44.5\%), children schooling (18.6\%), sense of belongings (14.8\%), adjacent to work $(13.8 \%)$ and quality of neighbourhood amenities $(7.6 \%)$ were the main elements marked by the respondents. According to the ranking of percentage of marked respondents, affordable housing is the dominant factor affecting the residents' intention of moving. Given 'affordable and diverse housing provision' was included into the social sustainability dimension of many different Neighbourhood Sustainability Assessment Tools (BeamPlus Neighbourhood, 2016; BREEAM Communities 2012; LEED-ND, 2016), its role in influencing the social sustainability, particularly those factors associated with the population stability, is highlighted in the context of China.

\subsection{The higher dependence and sensitive demand of the elderly on neighbourhood amenities}

\begin{tabular}{|c|c|c|c|c|c|}
\hline & Order & $\begin{array}{l}\text { The None-Elderly（from } 1 \\
\text { years old） }\end{array}$ & to 59 & The Elderly ( 60 years old 0 & bove) \\
\hline \multirow{7}{*}{$\begin{array}{l}\text { The ranking of the } \\
\text { percentage of } \\
\text { respondents who } \\
\text { selected the amenity as } \\
\text { frequently used one. }\end{array}$} & 1 & D6.Supermarket & $85.5 \%$ & D3. Fresh Market & $90.3 \%$ \\
\hline & 2 & D3. Fresh Market & $79.6 \%$ & D6.Supermarket & $79.1 \%$ \\
\hline & 3 & D4. Restaurant & $74.6 \%$ & D4. Restaurant & $56.3 \%$ \\
\hline & 4 & D2.Convenience Store & $65.8 \%$ & E5. Bus Station & $48.4 \%$ \\
\hline & 5 & $\begin{array}{l}\text { D8. Deliver \& Pick up } \\
\text { Station }\end{array}$ & $60.4 \%$ & $\begin{array}{l}\text { F6. Community Sitting-out } \\
\text { Area }\end{array}$ & $48.2 \%$ \\
\hline & 6 & E5. Bus Station & $59.2 \%$ & C5.Pharmacy & $46.1 \%$ \\
\hline & 7 & E6. Subway Station & $50.0 \%$ & D2.Convenience Store & $42.6 \%$ \\
\hline \multirow{7}{*}{$\begin{array}{l}\text { The ranking of the } \\
\text { percentage of } \\
\text { respondents who } \\
\text { selected the amenity to } \\
\text { be urgently improved. }\end{array}$} & 1 & $\begin{array}{l}\text { F6. Community Sitting-out } \\
\text { Area }\end{array}$ & $25.5 \%$ & $\begin{array}{l}\text { F6. Community Sitting-out } \\
\text { Area }\end{array}$ & $30.0 \%$ \\
\hline & 2 & E4. Parking Lots & $23.4 \%$ & F1. Fitness Area & $29.3 \%$ \\
\hline & 3 & F1. Fitness Area & $20.8 \%$ & F5. Elderly Activities & $24.9 \%$ \\
\hline & 4 & D3. Fresh Market & $16.0 \%$ & Eentrerblic Toilets & $19.8 \%$ \\
\hline & 5 & E1. Public Toilets & $10.7 \%$ & E4. Parking Lots & $18.7 \%$ \\
\hline & 6 & E3. Garbage Collection & $10.6 \%$ & D3. Fresh Market & $13.3 \%$ \\
\hline & 7 & $\begin{array}{l}\text { 5. Property } \\
\text { Management }\end{array}$ & $9.9 \%$ & C1. Community Hospitals & $11.5 \%$ \\
\hline
\end{tabular}

Table 2 The ranking of usage percentage and perceived to-be-improved amenities

The study used 'over $50 \%$ of the respondents indicated they frequently used this amenity' to define the frequently used amenity. For the sum of the types of frequently used amenities, there are total 7 types for the non-elderly group while there are only 3 for the elderly group. However, individually, there are 6 types of amenities that percentage of elderly frequent users is significantly larger than that of non-elderly frequent users, which include fresh market, neighbourhood park, pharmacy, outdoor working out area, healthcare center and neighbourhood service station. This results show that the elderly frequently-used amenities mainly concentrated on some specific ones of which they are the major users.

Meanwhile, the results of Spearman correlation analysis show that the neighbourhood satisfaction of elderly are more correlated with the neighbourhood amenities compared with the younger groups. The types of amenities which owns higher impact (the correlation coefficient is larger than 0.3 ) on the neighbourhood satisfaction of elderly group are more than those 
of youngster and middle-age groups. The correlation coefficient between neighbourhood satisfaction and the following amenities are all larger than 0.3 for elderly group: elderly service center, property management office, fitness area, reading room, neighbourhood square and neighbourhood service center. In comparison, there is only one type for the youngster and middle-age groups, which is bus station and property management office respectively. Generally, the results imply the higher degree of dependence of elderly quality of neighbourhood life on neighbourhood amenities.

\section{The application of IPA-Kano model in prioritizing the improvement of amenities satisfying the elderly at old danwei neighbourhood.}

By sorting out all the respondents at old neighbourhood who are older than 60 years, 482 samples of questionnaire have been obtained for modelling. The result of regression show that there are 20 out of total 23 factors significantly associating with overall neighbourhood satisfaction. According to the results of significant factors and the performance of each variable (the mean value of satisfaction), the 20 variables were categorized into nine specific groups with reference to the matrix formed, as shown in table 3. Then the priority of amenities improvement can be identified by the method in table 4 .

\begin{tabular}{|l|l|l|l|}
\hline & Basic Factors & Important Performance Factors & Exciting Factors \\
\hline Good performance & Restaurant & $\begin{array}{l}\text { Deliver \& Pick Up } \\
\text { Station/Community Hospitals/ } \\
\text { Pharmacy/Bus Station }\end{array}$ & Convenience Store \\
\hline Moderate performance & $\begin{array}{l}\text { Other Admin / } \\
\text { Service Station }\end{array}$ & $\begin{array}{l}\text { Privately-Owned Education And } \\
\text { Training Center /Chess Room }\end{array}$ & $\begin{array}{l}\text { Fresh Market/Bank } \\
\text { Branch/Kindergarten/Public } \\
\text { Toilets/Neighbourhood Service } \\
\text { Center }\end{array}$ \\
\hline Poor performance & $\begin{array}{l}\text { Reading } \\
\text { Room/Elderly } \\
\text { Service Station }\end{array}$ & $\begin{array}{l}\text { Property Management } \\
\text { Center/Neighbourhood } \\
\text { Square/Garbage Collection } \\
\text { Point/Parking Lots }\end{array}$ & \\
\hline
\end{tabular}

Table 3 The Three Factor and Performance Matrix

\begin{tabular}{|l|l|l|}
\hline Improvement Priority & Factors Category & Performance Level \\
\hline $\mathbf{1}$ & Basic Factors & Poor \\
\hline $\mathbf{2}$ & Important Performance Factors & Poor \\
\hline $\mathbf{3}$ & Basic Factors & Moderate \\
\hline $\mathbf{4}$ & Important Performance Factors & Moderate \\
\hline $\mathbf{5}$ & Exciting Factors & Poor \\
\hline 6 & Exciting Factors & Moderate \\
\hline
\end{tabular}

Table 4 The Identification Method of The Improvement Priority

Based on table 3 to table 4, the specific priorities of amenities improvement for satisfying the elderly at urban old danwei neighbourhoood can be proposed. To improve the elderly satisfaction towards neighbourhood amenities, the group of amenities which should be firstly improved are reading room, elderly service station, property management center, neighbourhood square, garbage collection point, parking lots. The subsequent group of amenities to be improved include: other administrative facilities, education and training center, Chess Room. The group of amenities to be lastly improved are fresh market, bank branch, kindergarten, public toilets and neighbourhood service center.

\section{Policy Implications and Recommendation}

This study pioneers the application of importance-performance analysis and three-factor theory to investigate the associations between the residential perception of various amenities provision and neighbourhood satisfaction. The IPA-Kano Model adopted implicit importance (deprived importance) to differentiate the three categories of factors that have different effects on the formulation of residential satisfaction with neighbourhood life. By integrating the three groups of 
factors and their actual performances, the study have identified improvement priorities for the amenities provision to improve the elderly satisfaction with neighborhood life at urban old danwei neighbourhood. This study also suggests that there is no universal approach fitting into all the different types of neighbourhoods. Instead, the improvement priorities for neighbourhood amenity vary among different contexts of neighbourhood. This results support the existing national policy of guiding the revitalization of old neighbourhoods by types and sequence. In addition, the study proposed specific people-oriented method for including residential subjective perception into determining the improvement priorities. Similar application can be explored in addressing different scenarios, such as the improvement priorities for suburban old danwei neighbourhoods or for those resettled neighbourhood where low-income residents living in. The identified priorities allow local governments to deploy scarce resources to effectively improve the satisfaction with neighbourhood life of existing residents (Yin et.al., 2016). In addition, it may help attracting more residents elsewhere to settle down.

\section{References}

Asiyanbola, R., Raji, B. and Shaibu, G. (2012), “Urban liveability in Nigeria: a pilot study of Ago Iwoye and Ijebu Igbo, Ogun state", Journal of Environmental Science and Engineering, Vol. B1 No. 10, pp. 1203-1213.

Bardhan, R., Kurisu, K., \& Hanaki, K. (2015). Does compact urban forms relate to good quality of life in high density cities of India? Case of Kolkata. Cities, 48, 55-65.

Campbell A, Converse PE, Rodgers WL. The Quality of American Life. New York : Russell Sage Foundation, 1976. Campbell, A., Converse, P., \& Rosders, W. (1976). The quality of American life: Perceptions, evaluations and satisfactions. New York: Russell Sage Foundation.

Cao, X. , Wu, X. , \& Yuan, Y. Examining Built Environmental Correlates of Neighborhood Satisfaction: A Focus on Analysis Approaches. Journal of Planning Literature, 2018, 33(4).

Diener, E., Oishi, S., \& Lucas, R. (2012). Subjective well-being: The science of happiness and life satisfaction. In S. Lopez, \& C. Snyder (Eds.). The Oxford handbook of positive psychology(2nd ed.). Oxford: Oxford University Press.

Dong, H., \& Qin, B. (2017). Exploring the link between neighbourhood environment and mental wellbeing: A case study in Beijing, China. Landscape and Urban Planning, 164, 71-80.

Dong, W; Cao, X.Y.; Wu, X.Y.; Dong, Y. (2019). Examining pedestrian satisfaction in gated and open communities: An integration of gradient boosting decision trees and impact-asymmetry analysis. Landscape and Urban Planning, 185(), 246-257.

Fernandez-Portero, C., Alarcon, D., \& Padura, A. (2017). Dwelling conditions and life satisfaction of older people through residential satisfaction. Journal of Environmental Psychology, 49, 1-7.

Iyanda, S.A. and Mohit, A. (2016), "Measuring the dimension and attributes of liveability of low income communities in Nigeria", Journal of Malaysian Institute of Planners, Vol. 14 No. 4, pp. 383-394.

Kano, N., Seraku, N., Takahashi, F., \& Tsuji, S. (1984). Attractive quality and must-bequality. Hinshitsu, 14(2), 147e156.

Liu, Y., Zhang, F., Wu, F., Liu, Y., \& Li, Z. (2017). The subjective wellbeing of migrants in Guangzhou, China: The impacts of the social and physical environment. Cities, 60, 333-342.

Matzler, K., \& Renzl, B. (2007). Assessing asymmetric effects in the formation of employee satisfaction. Tourism Management, 28, 1093-1103.

Mikulic, J., and D. Prebezac . "Accounting for dynamics in attribute-importance and for competitor performance to enhance reliability of BPNN-based importance - performance analysis." Expert Systems with Applications 39.5(2012):5144-5153. 
Mitchell, J.A. (2017) 'Changes to citation formats shake the research world', The Mendeley Telegraph (Weekend edition), 6 July, pp.9-12.

Mitchell, J.A. 'How citation changed the research world', The Mendeley, 62(9), p70-81.

Mitchell, J.A. 'How citation changed the research world', The Mendeley, 62(9) [online]. Available at: https://www.mendeley.com/reference-management/reference-manager (Accessed: 15 November 2016)

Mitchell, J.A. and Thomson, M. (2017) A guide to citation. 3rd edn. London: London Publishings.

Mitchell, J.A., Thomson, M. and Coyne, R.P. (2017) A guide to citation. E-book library [online]. Available at: https://www.mendeley.com/reference-management/reference-manager (Accessed: 10 September 2016)

Rashid, S.T., Ngah, N.B. and Eluwa, S.E. (2013), "Neighbourhood choice factors and residents satisfaction in old and new neighbourhoods of Slemani city, Kurdistan-Iraq", Journal of Environment and Earth Science, Vol. 3 No. 2, pp. 72-80.

Troy B.N. (2015) 'Harvard citation rules' in Williams, S.T. (ed.) A guide to citation rules. New York: NY Publishers, pp. 34-89.

Oluwunmi, A.O., Akinjare, O.A. and Izobo-Martins, O.O. (2012), "User's satisfaction with residential facilities in Nigerian private universities: a study of covenant university", Transnational Journal of Science and Technology, Vol. 2 No. 11, pp. 89-112.

William, S.T. (eds.) (2015) Referencing: a guide to citation rules. New York: My Publisher

Wu, X., Cao, X., \& Huting, J. (2018). Using the three-factor theory to identify improvement priorities for express and local bus services: An application of regression with dummy variables in the Twin Cities Transportation Research Part A 113, 184-196.

Yin, J.B.;Cao, X.Y.; Huang.X.Y; \& Cao,X.S., (2016). Applying the IPA-Kano model to examine environmental correlates of residential satisfaction: A case study of Xi'an[J]. Habitat International,53:

Yuan, Y; Ding, K.L; Cao, X.Y.; Wu, X.Y.. (2018) 'The Review of Research Methods on Neighbourhood Satisfaction and Influencing Factors', Urban Development Studies, 255 (10), 105-111.

Rohe, W. M. . (2009). From local to global: one hundred years of neighborhood planning. Journal of the American Planning Association. 75(2), 209-230.

Wu, X. , \& Cao, X. . (2017). Using the Three-Factor Method to Identify Improvement Priorities for Express and Local Bus Services in the Twin Cities, Minnesota.

Dong, W.; Cao, X.Y; Wu, X.Y. \& Dong, Y. (2019). Examining pedestrian satisfaction in gated and open communities: an integration of gradient boosting decision trees and impact-asymmetry analysis - sciencedirect. Landscape and Urban Planning, 185(C), 246-257. 